https://helda.helsinki.fi

Sauna bathing, health, and quality of life among octogenarian men: the Helsinki Businessmen Study

\title{
Strandberg, Timo
}

2018-09

Strandberg , T , Strandberg , A , Pitkälä , K \& Benetos , A 2018 , ' Sauna bathing, health, and quality of life among octogenarian men: the Helsinki Businessmen Study ', Aging

Clinical and Experimental Research , vol. 30 , no. 9 , pp. 1053-1057 . https://doi.org/10.1007/s40520-017-0855-z

http://hdl.handle.net/10138/304106

https://doi.org/10.1007/s40520-017-0855-z

publishedVersion

Downloaded from Helda, University of Helsinki institutional repository.

This is an electronic reprint of the original article.

This reprint may differ from the original in pagination and typographic detail.

Please cite the original version. 


\title{
Sauna bathing, health, and quality of life among octogenarian men: the Helsinki Businessmen Study
}

\author{
Timo E. Strandberg ${ }^{1,2}$ (D) Arto Strandberg ${ }^{1} \cdot$ Kaisu Pitkälä ${ }^{1} \cdot$ Athanase Benetos $^{3}$
}

Received: 5 September 2017 / Accepted: 7 November 2017 / Published online: 29 November 2017

๑) Springer International Publishing AG, part of Springer Nature 2017

\begin{abstract}
Background and aim Sauna-type bathing has increased worldwide, and it has been related to both harmful and beneficial effects. There are few studies of bathing in sauna in very old age.

Methods The series consists of 524 mostly home-living survivors of the Helsinki Businessmen Study (HBS, mean age 86 years, range 80-95), who in 2015 responded to a questionnaire survey about lifestyle (including sauna bathing), prevalent diseases, and health-related quality of life (HRQoL, RAND-36).

Results Of the men 57.6\% $(n=302)$ reported all-year round and $17.6 \%(n=92)$ part-year sauna bathing. Sauna was currently used mostly once a week, but $10 \%$ bathed more than twice a week. Median time in the hot room was 15 min at $80^{\circ} \mathrm{C}$. Among 45.7\% of the men, the habit had decreased with ageing, and 130 (24.8\%) did not attend sauna. However, 92.2\% of the latter had discontinued an earlier habit, respective proportions $20.7 \%$ and $75.0 \%$ among all-year and part-year users. Overall, reasons for decreased sauna bathing were nonspecific or related to mobility problems or diverse health reasons $(n=63)$. The most frequent motivations for sauna were relaxation and hygienic reasons. Of the RAND-36 domains physical function, vitality, social functioning, and general health were significantly better among sauna users than non-users. These differences partly remained after adjusting for prevalent diseases and mobility-disability.

Conclusions Regular sauna bathing was common among octogenarian men and was associated with better HRQoL. However, reverse causality must be taken into account in this cross-sectional study. The bathing habit seemed to be prudent and had decreased in almost half of the cohort.
\end{abstract}

Keywords Sauna $\cdot$ Lifestyle $\cdot$ Quality of life $\cdot$ Waon therapy $\cdot$ Aged $\cdot$ Health

\section{Introduction}

Typical Finnish sauna bathing (http://www.saunasociety. org/sauna-types/) includes several short visits (2-20 min) in a relatively dry, hot room heated with a stove covered by hot rocks, interrupted by cooling-off periods and possibly swimming. Typical temperature is $80-100{ }^{\circ} \mathrm{C}$ with relative humidity of $10-20 \%$.

Timo E. Strandberg

timo.strandberg@oulu.fi

1 University of Helsinki, Clinicum, and Helsinki University Hospital, Haartmaninkatu 4, PO Box 340, 00029 Helsinki, Finland

2 Center for Life Course Health Research, University of Oulu, Oulu, Finland

3 University Hospital of Nancy, Université de Lorraine, Nancy, France
Exposure to heat in the form of sauna bathing or hot tub has various cardiovascular and metabolic effects, and it has raised interest in the prevention and treatment of chronic diseases [1-9]. In the past, sauna bathing raised concerns of especially cardiovascular hazards [10-12], but these have been abolished-at least when sauna bathing is "prudent" [13-16], i.e. not too hot, not too long, and not bathing when intoxicated. Paradoxically, recent epidemiologic reports suggest less cardiovascular mortality, hypertension and dementia associated with frequent sauna bathing in midlife [17-19]. These could be explained by beneficial effects of heat in the vasculature, e.g. endothelial [3] and metabolic functions $[1,20]$, which may be accentuated among older people and cardiovascular patients $[8,9]$. In analogy with diet therapy, which can be carried out as a single modification (e.g. fat, protein) or holistically as a pattern (e.g. the Mediterranean diet), instead of legs in a hot tub, heat therapy can be given as sauna bathing which also has social and 
overall well-being dimensions. On the other hand, there are limited data of sauna bathing and relationships to health and disease in people aged 80 years and over.

In the present study, we have studied a large group of men aged 81-96 years, and related their sauna habits to personal characteristics, diseases, and health-related quality of life (HRQoL).

\section{Methods}

\section{Participants}

The HBS cohort (original $n=3490$ ) has been described in detail earlier [21]. HBS consists of white men born between 1919 and 1934 belonging to the highest social strata, with similar socioeconomic status during their working life. HBS has been registered as ClinicalTrials.gov identifier: NCT02526082, and the follow-up has been approved by the ethical committee of the Helsinki University Hospital, Finland.

Since 2000, postal questionnaires about demographics, lifestyle, physician-diagnosed diseases, and medications have regularly been sent to the surviving cohort members. The questionnaire has every time included the RAND-36/ SF-36 HRQoL instrument [22], which comprises eight domains: physical functioning (PF), role limitations caused by physical health problems (RP), Role limitations caused by emotional problems (RE), vitality (VT), mental health $(\mathrm{MH})$, social functioning (SF), bodily pain (BP), and general health $(\mathrm{GH})$. scores range from zero to 100 , with 100 representing the best level of functioning or wellbeing. A difference of three to five points in the RAND-36 domains is considered to be clinically important [23]. Mobility-disability was defined as reporting a lot of difficulties in walking half a kilometer.

Vital status and addresses have been sought from the Finnish Population Information System Register Centre. The response rate has been satisfactory, although decreasing with ageing of the cohort.

In the 2015 survey, we also included questions about habits of bathing in sauna (frequency, time, and temperature), whether the habit has changed with ageing, and reasons for change. Because in Finland, bathing in sauna may be concentrated in summer months, all-year and part-year sauna bathing were differentiated, but combined in some of the analyses. The present analytic cohort consisted of all those 524 men, $92 \%$ of them home-living, who reported their sauna bathing habits in the 2015 survey.

\section{Statistical analyses}

Analysis of covariance (ANCOVA, trend test) was used where appropriate to compare continuous variables [mean with standard deviation (SD) or standard error (SE)] across sauna bathing groups. Chi-square and trend tests were used to compare proportions. Logistic regression was used to investigate independent relationships with sauna bathing, these results are presented as odds ratios (OR) with their 95\% confidence intervals (CI). In statistical analyses twosided $p$ values are given. The statistical software NCSS (version 2004, http://www.ncss.com, Kaysville, UT, USA) was used for the statistical analyses.

\section{Results}

General characteristics of the cohort according to sauna habits are shown in Table 1. Mean age of the cohort was 86.4 years (range $80-96$ years), those avoiding sauna bathing being on the average 1 year older, and they tended to consume less alcohol. The men with current habit of sauna bathing reported more often regular weekly exercise and had less heart failure and musculoskeletal disorders. Otherwise, there were no significant differences in lifestyle or diseases, including coronary artery disease, arrhythmias, or pulmonary diseases. In the age-adjusted logistic regression analyses, reported heart failure, musculoskeletal disease, or mobility-disability were associated with higher odds of not using sauna 2.3 and 1.7 and 2.5-fold, respectively (OR 2.3, 95\% CI 1.4-3.8; 1.7, 95\% CI 1.2-2.6; 2.5, 95\% CI 1.4-4.3).

Although cross-sectionally $24.8 \%$ reported not currently visiting sauna, $92.2 \%$ of them had decreased an earlier habit. A decrease was also observed in 20.7 and $75.0 \%$ of all-year and part-year sauna bathers, respectively. Overall, reasons for decreasing sauna bathing were nonspecific or related to mobility problems, and only one-third $(n=63)$ reported some reason(s) related to health or disease. The most frequent motivations for sauna bathing were relaxation and hygienic reasons.

Relationships between HRQoL and sauna bathing are shown in Table 2. Of the RAND-36 scales, not bathing in sauna was significantly associated with age-adjusted lower values in physical function, vitality, social functioning, and general health. Further adjustment for diseases did not materially change the relationships. Differences in physical function and vitality also prevailed after adjusting for mobilitydisability. Notably, mental health or perceived pain were not related to sauna bathing. 
Table 1 Characteristics of the analytical cohort according to sauna bathing in 2015

\begin{tabular}{|c|c|c|c|c|c|}
\hline \multirow[t]{2}{*}{ Variable $^{\mathrm{a}}$} & \multirow{2}{*}{$\begin{array}{l}\text { All } \\
n=524\end{array}$} & \multicolumn{4}{|l|}{ Sauna bathing } \\
\hline & & $\begin{array}{l}\text { Regular all year } \\
\text { round, } n=302\end{array}$ & Part of year, $n=92$ & None, $n=130$ & $\begin{array}{l}P \text { value for dif- } \\
\text { ference between } \\
\text { groups }\end{array}$ \\
\hline Age (year) & $86.4(0.2)$ & $86.1(0.2)$ & $86.1(0.3)$ & $87,1(0.3)$ & 0.015 \\
\hline Home-living & $501(95.6)$ & $286(94.7)$ & $89(96.7)$ & $116(89.2)$ & 0.055 \\
\hline Mobility-disability ${ }^{\mathrm{b}}$ & $65(12.4)$ & $28(9.3)$ & $9(9.8)$ & $28(21.5)$ & $<0.001$ \\
\hline Good or moderate economic situation & $519(99.0)$ & $299(99.0)$ & $92(100)$ & $130(100)$ & 0.43 \\
\hline BMI, $\mathrm{kg} / \mathrm{m}^{2}$ & $24.9(0.3)$ & $25.0(0.2)$ & $24.8(0.4)$ & $24.8(0.3)$ & 0.87 \\
\hline Nonsmokers & $505(96.4)$ & $292(96.7)$ & 89 (96.7) & $124(95.4)$ & 0.39 \\
\hline Alcohol consumption, gr/week & $61.9(5.5)$ & $59.8(4.8)$ & $77.0(8.7)$ & $48.9(7.3)$ & 0.049 \\
\hline Regular weekly exercise & $381(72.7)$ & $242(80.1)$ & $63(68.5)$ & $76(58.5)$ & $<0.001$ \\
\hline None or slight subjective memory disorder & $467(89.1)$ & $271(89.7)$ & $84(91.3)$ & $112(86.2)$ & 0.66 \\
\hline \multicolumn{6}{|l|}{ Physician-diagnosed conditions } \\
\hline Hypertension & $273(52.1)$ & $164(54.3)$ & $49(53.2)$ & $60(46.2)$ & 0.30 \\
\hline Diabetes & $86(16.4)$ & $46(15.2)$ & $14(15.2)$ & $26(20.0)$ & 0.43 \\
\hline Chronic arrhythmia & $152(29.0)$ & $92(30.5)$ & $26(28.2)$ & $34(26.2)$ & 0.65 \\
\hline Coronary artery disease & $116(22.1)$ & $58(19.2)$ & $20(21.7)$ & $38(29.2)$ & 0.067 \\
\hline Stroke or TIA & $64(12.2)$ & $32(10.6)$ & $15(16.3)$ & $17(13.1)$ & 0.34 \\
\hline Heart failure & $86(16.4)$ & $39(12.9)$ & $13(14.1)$ & $34(26.2)$ & 0.002 \\
\hline Pulmonary disease & $56(10.7)$ & $30(9.9)$ & $10(10.9)$ & $16(12.3)$ & 0.76 \\
\hline Cancer & $111(21.2)$ & $56(18.5)$ & $24(26.1)$ & $31(23.8)$ & 0.22 \\
\hline Musculoskeletal disease & $175(33.4)$ & $96(31.8)$ & $24(26.1)$ & $55(42.3)$ & 0.022 \\
\hline
\end{tabular}

$B M I$ body mass index, TIA transient ischemic attack

${ }^{a}$ Continuous variables are mean (SE), categorical variables are reported as number (\%)

${ }^{\mathrm{b}}$ Defined as a lot of difficulties in walking half a kilometer

Table 2 Health-related quality of life according to sauna bathing habits in 2015

\begin{tabular}{|c|c|c|c|c|c|c|}
\hline \multirow[t]{2}{*}{ RAND-36 scale } & \multicolumn{3}{|l|}{ Sauna bathing } & \multicolumn{3}{|c|}{$P$ value for difference between groups (trend test) } \\
\hline & $\begin{array}{l}\text { Regular all year } \\
\text { round, } n=302^{\mathrm{a}}\end{array}$ & Part of year, $n=92$ & None, $n=130^{\mathrm{a}}$ & Age-adjusted & $\begin{array}{l}\text { Adjusted for age, heart } \\
\text { failure, and musculoskeletal } \\
\text { disease }\end{array}$ & $\begin{array}{l}\text { Further adjusted for } \\
\text { mobility-disability }\end{array}$ \\
\hline Physical functioning & $69.9(1.4)$ & $69.3(2.5)$ & $54.3(2.2)$ & $<0.001$ & $<0.001$ & $<0.001$ \\
\hline $\begin{array}{l}\text { Role limitations } \\
\text { caused by physical } \\
\text { health problems }\end{array}$ & $61.4(2.3)$ & $56.7(4.3)$ & $57.7(3.6)$ & 0.51 & 0.52 & 0.39 \\
\hline $\begin{array}{l}\text { Role limitations } \\
\text { caused by emo- } \\
\text { tional problems }\end{array}$ & $70.5(2.1)$ & $69.0(3.8)$ & $71.6(3.4)$ & 0.88 & 0.58 & 0.26 \\
\hline Vitality & $67.0(1.1)$ & $66.8(2.0)$ & $57.9(1.8)$ & $<0.001$ & 0.002 & 0.011 \\
\hline Mental health & $81.6(0.8)$ & $82.6(1.5)$ & $79.7(1.3)$ & 0.32 & 0.57 & 0.91 \\
\hline Social functioning & $83.5(1.2)$ & $83.3(2.2)$ & $75.4(1.9)$ & 0.0012 & 0.019 & 0.069 \\
\hline Bodily pain & $78.0(1.2)$ & $76.1(2.2)$ & $77.2(1.9)$ & 0.75 & 0.29 & 0.065 \\
\hline General health & $57.7(1.0)$ & $58.1(1.8)$ & $52.2(1.6)$ & 0.0093 & 0.049 & 0.50 \\
\hline
\end{tabular}

Variables are mean (SE) 


\section{Discussion}

Sauna bathing was common among octogenarian, mainly home-living Finnish men. Only a quarter of them reported not regularly bathing in sauna. Even among those avoiding sauna, over $90 \%$ had had an earlier regular sauna habit. A decrease in sauna bathing was mainly reported to be due to nonspecific reasons or mobility problems, and only 63 men reported reasons attributed to health. In comparison between sauna bathers and non-bathers, heart failure, musculoskeletal diseases, or the presence of mobility-disability were associated with higher odds of not attending sauna anymore. In accordance, items related to physical HRQoL were better among sauna bathers.

Several clinical studies have shown that sauna bathing of the Finnish type, with temperatures $80-100{ }^{\circ} \mathrm{C}$, is safe even for cardiovascular patients without serious conditions such as aortic stenosis [13-16]. This evidently includes that alcohol intoxication or other accident-prone behaviour leading to, e.g. burns [24] is avoided. The present results extend these re-assuring notions in the sense that regular sauna bathing was common among octogenarian men. New epidemiological research even suggests that sauna bathing may have beneficial consequences for ageing populations. In a long-term study, frequent Finnish sauna bathing in midlife was subsequently associated with less hypertension, cardiovascular mortality, and dementia [17-19]. While these associations have aroused international interest in benefits [25], they may simply be due to reverse causality, i.e. "the healthy user effect" may be in play [26, 27]. On the other hand, clinical and experimental studies of heat therapy on vascular function and metabolism demonstrate beneficial effects which could explain the epidemiological findings [3, 6-9, 28]. It is possible, that sauna bathing induces a hormesis effect, i.e. a mild stress response leading to beneficial physiological consequences [29].

Furthermore, Japanese researchers have developed a special form of sauna, "Waon therapy", which in several studies has shown to be beneficial for heart failure patients [30-34]. In the Waon-type sauna, temperature is milder, $60^{\circ} \mathrm{C}$, and it is dryer than in the traditional Finnish sauna with temperatures $80-100{ }^{\circ} \mathrm{C}$ and relative humidity $10-20 \%$. Waon therapy is more "clinical", and therefore, lacking the social dimensions of traditional Finnish-type sauna bathing, but on the other hand it can be more easily accessible for patients with mobility problems; in our study mobility-disability was strongly associated with not attending sauna. It is interesting to note that in one study Waon therapy improved the same items of HRQoL (physical function, vitality) as observed in our study [34]. However, in these studies the patients have been on the average 60 years of age, and the experience among older heart failure patients is sparse.
Considering the potential benefits for patients with heart failure, it is paradoxical that in our study the presence of this condition was associated with less sauna bathing. A possible explanation is that sauna has been forbidden for these patients by the treating physician. In the light of all evidence, bathing in lower temperatures could be beneficial for persons with heart failure.

\section{Strengths and limitations}

The strengths of our study include the homogenous cohort where socioeconomic or cultural factors are not likely to affect sauna bathing. At the same time, the inclusion of Finnish men with heavy cultural tradition for sauna bathing limits the generalizability of the results. Limitations also include the cross-sectional design, and the self-reporting of diseases. The possibility of reverse causality cannot be avoided in a cross-sectional study, and it is possible that those men with good quality of life and good health are more inclined to bathing in sauna. However, follow-up of the cohort is ongoing, and it will be possible to relate sauna bathing to future events.

\section{Conclusions}

The results show that regular sauna bathing can be common also in the oldest-old, and if further research confirms clinical benefits, sauna bathing could be developed into a form of therapy to improve health and wellbeing.

\section{Compliance with ethical standards}

Funding This work was supported by the Helsinki University Hospital [Valtion tutkimusrahoitus TYH2014 and TYH2015 to T.E.S], and Academy of Finland (Grant 311492).

Conflict of interest The authors report no conflicts of interest.

Ethical approval The Helsinki Businessmen Study had ethical approval from the Ethics Committee of the Department of Medicine, Helsinki University Hospital.

Statement of human and animal rights All procedures performed in this study involving human participants were in accordance with the ethical approval and standards of the institutional research committee.

Informed consent All participants gave written informed consent.

\section{References}

1. Hooper PL (1999) Hot-tub therapy for type 2 diabetes mellitus. N Engl Med 341:924-925 
2. Crandall CG, González-Alonso J (2010) Cardiovascular function in the heat stressed human. Acta Physiol [Oxf] 199:407-423. https://doi.org/10.1111/j.1748-1716.2010.02119.x

3. Brunt VE, Howard MJ, Francisco MA et al (2016) Passive heat therapy improves endothelial function, arterial stiffness and blood pressure in sedentary humans. J Physiol 18:5329-5342

4. Hooper PL, Balogh G, Rivas E et al (2014) The importance of the cellular stress response in the pathogenesis and treatment of type 2 diabetes. Cell Stress Chaperones 19:447-464

5. Gagnon D, Romero SA, Ngo H et al (2016) Healthy aging does not compromise the augmentation of cardiac function during heat stress. J Appl Physiol 121:885-892. https://doi.org/10.1152/ japplphysiol.00643.2016

6. Brunt VE, Eymann TM, Francisco MA et al (2016) Passive heat therapy improves cutaneous microvascular function in sedentary humans via improved nitric oxide-dependent dilation. J Appl Physiol 121:716-723. https://doi.org/10.1152/ japplphysiol.00424.2016

7. Romero SA, Gagnon D, Adams A et al (2016) Acute limb heating improves macro- and microvascular dilator function in the leg of aged humans. Am J Physiol Heart Circ Physiol 312:H89-H97. https://doi.org/10.1152/ajpheart.00519 2017.

8. McGinn R, Poirier MP, Kenny GP (2017) Using heat as a therapeutic tool for the aging vascular tree. Am J Physiol Heart Circ Physiol 312:H806-H807. https://doi.org/10.1152/ ajpheart.00519.2016

9. Kenny GP, Poirier MP, Metsios GS et al (2017) Hyperthermia and cardiovascular strain during an extreme heat exposure in young versus older adults. Temperature 4:79-88. https://doi.org/10.108 0/23328940.2016.1230171

10. Romo M (1976) Heart attacks and the sauna. Lancet 313:809

11. Cooperman EM (1978) The sauna: a health hazard? CMAJ 118:1024

12. Hawkins C (1987) The sauna: killer or healer? Br Med J 295:1015-1016

13. Luurila OJ (1978) Cardiac arrhythmias, sudden death and the Finnish sauna bath. Adv Cardiol 25:73-81

14. Eisalo A, Luurila OJ (1988) The Finnish sauna and cardiovascular diseases. Ann Clin Res 20:267-270

15. Kukkonen-Harjula K, Kauppinen K (2006) Health effects and risks of sauna bathing. Int J Circumpolar Health 65:195-205

16. Hannuksela M, Ellahham S (2001) Benefits and risks of sauna bathing. Am J Med 110:118-126

17. Laukkanen T, Khan H, Zaccardi F et al (2015) Association between sauna bathing and fatal cardiovascular and all-cause mortality events. JAMA Intern Med 175:542-548

18. Zaccardi F, Laukkanen T, Willeit P et al (2017) Sauna bathing and incident hypertension: a prospective cohort study. Am J Hypertens. https://doi.org/10.1093/ajh/hpx102 (Epub ahead of print)
19. Laukkanen T, Kunutsor S, Kauhanen J et al (2017) Sauna bathing is inversely associated with dementia and Alzheimer's disease in middle-aged Finnish men. Age Ageing 46:245-249

20. Krause M, Ludwig MS, Heck TG et al (2015) Heat shock proteins and heat therapy for type 2 diabetes: pros and cons. Curr Opin Clin Nutr Metab Care 18:374-380

21. Strandberg TE, Salomaa V, Strandberg AY et al (2016) Cohort profile: the Helsinki businessmen study [HBS]. Int J Epidemiol 45:1074-1074h

22. Aalto AM, Aro AR, Teperi J (1999) RAND-36 as a measure of health-related quality of life. Reliability, construct validity and reference values in the Finnish general population. Stakes, Research Reports, Helsinki No. 101

23. Hays RD, Morales LS (2001) The RAND-36 measure of healthrelated quality of life. Ann Med 33:350-357

24. Koljonen V (2009) Hot air sauna burns-review of their etiology and treatment. J Burn Care Res 30:705-710

25. Redberg R (2015) Health benefits of sauna bathing. JAMA Intern Med 175:548

26. Kivimäki M, Virtanen M, Ferrie JE (2015) The link between sauna bathing and mortality may be noncausal. JAMA Intern Med 175:1718

27. Epstein Y, Schoenfeld Y (2015) The link between sauna bathing and mortality may be noncausal. JAMA Intern Med 175:1718-1719

28. Gryka D, Pilch W, Szarek M et al (2014) The effect of sauna bathing on lipid profile in young, physically active, male subjects. Int J Occupat Med Environ Health 14:27:608-618

29. Cornelius C, Perrotta R, Graziano A et al (2013) Stress responses, vitagenes and hormesis as critical determinants in aging and longevity: mitochondria as a "chi”. Immunity Ageing 10:15

30. Tei C, Horikiri Y, Park JC et al (1995) Acute hemodynamic improvement by thermal vasodilation in congestive heart failure. Circulation 91:2582-2590

31. Kihara T, Biro S, Imamura M et al (2002) Repeated sauna treatment improves vascular endothelial and cardiac function in patients with chronic heart failure. J Am Coll Cardiol 39:754-759. https://doi.org/10.1016/S0735-1097[01]01824-1

32. Kihara T, Miyata M, Fukudome T et al (2009) Waon therapy improves the prognosis of patients with chronic heart failure. $J$ Cardiol 53:214-218. https://doi.org/10.1016/j.jjcc.2008.11.005

33. Kuwahata S, Miyata M, Fujita $S$ et al (2011) Improvement of autonomic nervous activity by Waon therapy in patients with chronic heart failure. J Cardiol 57:100-106. https://doi.org/10.1016/j. jjcc.2010.08.005

34. Sobajima M, Nozawa T, Fukui Y et al (2015) Waon therapy improves quality of life as well as cardiac function and exercise capacity in patients with chronic heart failure. Int Heart J 56:203208. https://doi.org/10.1536/ihj.14-266 